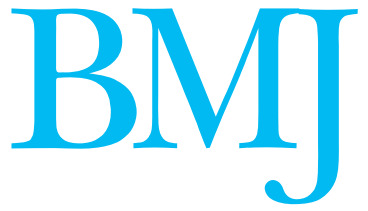

\title{
Severe community acquired pneumonia
}

\author{
Early switch from intravenous to oral antibiotics is safe and reduces hospital stay
}

$\mathrm{R}$

esearch into community acquired pneumonia over the past two decades has focused on developing tools to measure the severity of illness and which antibiotics to choose. Several tools can now help clinicians identify patients with severe community acquired pneumonia in clinical settings. ${ }^{1}$ In people with severe disease, international guidelines recommend early treatment with broad spectrum antibiotics, which provide cover for atypical pathogens. ${ }^{2}$

It is less clear how best to manage patients during their stay in hospital. In this week's BMJ, a randomised trial by Oosterheert and colleagues reports the effect of switching from intravenous to oral antibiotics after three days rather than seven days in people with severe community acquired pneumonia. ${ }^{3}$ Until now, the lack of quality trial data in areas such as route of antibiotic administration, duration of treatment, and assessment of clinical stability has led to a conservative approach to management and prolongation of hospital stay.

The National Health Service spends more than $£ 400 \mathrm{~m}$ (€592m; \$780m) a year on community acquired pneumonia. ${ }^{4}$ To reduce healthcare costs, length of hospital stay should be reduced without compromising patient safety. Our group has shown that clinicians' behaviour is the main determinant of variability in the duration of treatment with intravenous antibiotics. It outweighs all other factors, including patient characteristics, and is therefore the major determinant of length of hospital stay for patients with this disease. ${ }^{5}$ Provision of quality data is key to reducing the pronounced variability in clinical practice.

The trial by Oosterheert and colleagues provides more support for an early switch from intravenous to oral antibiotics. It found that such a switch was safe and reduced length of hospital stay (9.6 $v 11.5$ days; $95 \%$ confidence interval 0.6 to 3.2). ${ }^{5}$ One strength of the study was that it used clinical stability as the basis for switching from intravenous to oral treatment in the intervention arm. The time chosen to switch patients from intravenous to oral antibiotics was three days if clinical stability criteria were met (including respiratory rate $<25$ per minute, haemodynamic stability, and ability to take oral drugs). Data on the minimum safe duration of intravenous antibiotics in this context are still to be determined. During follow-up, only $2 \%$ of patients who were switched to early oral antibiotics needed to restart intravenous therapy.

The other aspect of the study relevant to length of BMJ 2006;333:1181-2 despite patients meeting predefined discharge criteria. This occurred even though the discharge criteria were more conservative than the stability criteria used for the intravenous to oral switch. The treating physician decided the time of discharge, and this decision will have been influenced by social factors and comorbidities specific to each patient. The authors suggest that incomplete resolution of all clinical signs of pneumonia delayed discharge even when patients were clinically stable. However, several observational studies found no advantage of observing inpatients once stability criteria comparable to those used in the current study were met. $^{67}$ This suggests that the current study used overly conservative discharge practices, and it would have been safe to shorten length of stay further for most patients. However, patients must be stable before discharge, as adverse outcomes have been reported in people discharged with clinical instability. $^{8}$

The challenge now is to design a new era of multicentre studies for community acquired pneumonia. Rather than continuing to search for the best antibiotic regimen, it is time to answer more pragmatic questions. Firstly, what degree of clinical stability needs to occur before switching to oral antibiotics given the pharmacokinetics and recognised modes of action of these drugs? $?^{9}$ If most $(81 \%)$ patients safely tolerated the switch from intravenous to oral antibiotics after three days then some may have tolerated the switch earlier; possibly at the first sign of clinical improvement or even after the first dose. Secondly, would further investigation of the criteria for clinical stability, combined with strategies that deal with social determinants, facilitate further reductions in length of stay without compromising patient safety or satisfaction? We have sufficient evidence to ensure that research into these questions is ethical.

The results of the study should give clinicians the confidence to switch clinically stable patients from intravenous to oral antibiotics at 72 hours, with consideration of early discharge thereafter. The traditional one size fits all approach to the management of community acquired pneumonia can no longer be justified.

Graham D Mills infectious diseases physician

(millsg@waikatodhb.govt.nz)

Waikato Hospital, Hamilton, New Zealand 3204

Richard Laing respiratory physician

Christchurch Hospital, Christchurch, New Zealand 8001 
Competing interests: GDM was reimbursed by Bristol-Myers Squibb for attending conferences and received consulting fees from ICOS Corporation. GDM also received research funds from GlaxoSmithKline, Boehringer Ingelheim, ICOS Corporation, Sanofi-Aventis, Roche, Pharmacia, and MSD. RL received support funding for staff from GlaxoSmithKline and Boehringer Ingelheim.

1 Buising KL, Thursky KA, Black JF, Street AC, Kennedy MP, Brown GV. A prospective comparison of severity scores for identifying patients with severe community acquired pneumonia: reconsidering what is meant by severe pneumonia. Thorax 2006;61:419-24.

2 Battleman DS, Callahan M, Howard TH. Rapid antibiotic delivery and appropriate antibiotic selection reduce length of hospital stay of patient with copriate antibiotic selection reduce length of hospital stay of patient

Wosterbert IJ Bonten MJM, Schneider MME Buskens E L,162.682-8.

Oosterheert JJ, Bonten MJM, Schneider MME, Buskens E, Lammers J-WJ,
Hustinx WMN, et al. Effectiveness of early switch from intravenous to oral antibiotics in severe community acquired pneumonia: multicentre randomised trial. BMJ 2006 doi: 10.1136/bmj.38993.560984.BE

4 Guest JF, Morris A. Community-acquired pneumonia: the annual cost to the National Health Service in the UK. Eur Respir J 1997;10:1530-4.

5 Laing R, Coles C, Chambers S, Frampton C, Jennings L, Karalus N, et al. Community-acquired pneumonia: influence of management practices on length of hospital stay. Intern Med J 2004;34:91-7.

6 Nathan RV, Rhew DC, Murray C, Bratzler DW, Houck PM, Weingarten SR. In-hospital observation after antibiotic switch in pneumonia: a national evaluation. Am J Med 2006;119:512-8.

7 Halm EA, Fine MJ, Marrie TJ, Coley CM, Kapoor WN, Obrosky S, et al. Time to clinical stability in patients hospitalized with communityacquired pneumonia. JAMA 1998;279:1452-7.

8 Halm EA, Fine MJ, Kapoor WN, Singer DE, Marrie TJ, Siu AL. Instability Halm EA, Fine MJ, Kapoor WN, Singer DE, Marrie TJ, Siu AL. Instability
on hospital discharge and the risk of adverse outcomes in patients with

pneumonia. Arch Intern Med 2002;162:1278-84.
Craig WA, Andes B. Parenteral versus oral antibiotic therapy. Med Clin North Am 1995;79:497-508.

doi 10.1136/bmj.39050.672639.80

\title{
Hajj and the risk of influenza
}

\author{
The threat can no longer be ignored
}

$\mathrm{A}$ $t$ the end of next month Saudi Arabia will again host the Hajj-the largest annual gathering in the world-which attracts more than two million pilgrims from almost every country on earth. ${ }^{12}$ For the individual pilgrim this is a deeply spiritual journey that represents the culmination of months if not years of preparation. From a public health perspective, however, such a gathering makes the possible rampant spread of the influenza virus and a global pandemic-which many experts believe is overdue-a potentially devastating prospect that has been inadequately prepared for. ${ }^{3}$

Recent work highlighting the high rates of infection and carriage of influenza virus in pilgrims returning from Mecca has emphasised the need for internationally agreed strategies to minimise the risk of a pandemic. ${ }^{4-6}$ Such a strategy should centre on ways to prevent transmission, but must also include facilities for prompt diagnosis and treatment of infected individuals. No such comprehensive strategy currently exists.

The Hajj and its associated rites are a once in a lifetime obligation for people who have the means to undertake the journey. The Hajj attracts ever increasing numbers of men, women, and children from a diverse array of ethnic, linguistic, and social backgrounds. ${ }^{2}$ Because the sacred rites are undertaken at the same time, overcrowding is considerable throughout the five day Hajj period. Accommodation is, of necessity, in tents in the desert plains of Mina and Arafat, and it is not unusual for 50-100 people to share a tent overnight. Such overcrowding and continuous close contact greatly increases the spread of respiratory infections. It has been estimated that more than one in three pilgrims will experience respiratory symptoms during their stay. ${ }^{4}$

The Saudi Arabian Ministry of Health has recommended that masks be used to minimise droplet spread, ${ }^{78}$ but many Muslims consider covering the face during the Hajj to be prohibited. In addition, masks need to be of a high quality and changed at least every six hours to remain effective, so general compliance with this advice is unlikely.
The Department of Health (for England) does not advise the use of masks, but frequent hand washing is recommended to reduce spread of the virus. Given the religious insistence on ritual purity before the five daily prayers and other acts of worship, this suggestion should be acceptable to most pilgrims and relatively easy to implement. ${ }^{9}$

Although the Saudi authorities currently recommend vaccination against influenza for pilgrims with "high risk" chronic illnesses such as pre-existing respiratory disorders, data from the United Kingdom indicate that many such high risk pilgrims remain unimmunised. ${ }^{10}$ The situation is probably far worse among the large numbers of people coming from the economically developing world. Given this fact and the risks of a pandemic originating from the Hajj, mandatory influenza vaccination for all pilgrims should be considered. ${ }^{11}$ Mandatory meningococcal vaccination was introduced after a meningococcal epidemic among pilgrims and their contacts. As pilgrims already need to seek medical attention to obtain a meningococcal vaccination, this extra vaccination should not be too inconvenient and should be readily acceptable.

Neuraminidase inhibitors can reduce the duration of the illness and its spread to household contacts. ${ }^{12}$ However, two practical difficulties need to be overcome before these drugs can be made available to pilgrims. Firstly, the high prevalence of general respiratory symptoms and the absence of state-of-theart diagnostic testing facilities make it difficult for infected people to be identified quickly. ${ }^{5}$ Early diagnosis is important for treatment to be effective, so near patient testing should be more readily available. The second difficulty lies in the cost of stock piling sufficient supplies for the numbers that may be affected and the logistical challenge of ensuring that household contacts of returning pilgrims are treated promptly.

Virus surveillance studies to identify newly emerging strains are needed urgently. Currently Saudi Arabia is not among the 100 centres around the world where such structured surveillance studies are being undertaken. ${ }^{4}$ The World Health Organization is still 
developing its strategy to prevent a possible influenza pandemic. WHO must work with the Saudi authorities to minimise the risk of the influenza virus spreading among pilgrims (and the rest of us). A coherent international response will be needed to ensure that the resources and logistics are in place so that these strategies can be implemented. ${ }^{13}$

\section{A Rashid Gatrad consultant paediatrician \\ Manor Hospital, Walsall WS2 2PS \\ Shuja Shafi consultant microbiologist}

Clinical Microbiology and Health Protection Agency Collaborating Laboratory, Northwick Park Hospital, Middlesex HA1 3UJ

Ziad A Memish consultant in infectious diseases

Gulf Cooperation Council States Centre for Infection Control, King Abdulaziz Medical City, PO Box 22490, Riyadh 11426, Kingdom of Saudi Arabia

Aziz Sheikh professor of primary care research and development

(aziz.sheikh@ed.ac.uk)

Allergy and Respiratory Research Group, Division of Community Health Sciences, GP Section, University of Edinburgh, Edinburgh EH8 9DX

Competing interests: None declared.
1 Gatrad AR, Sheikh A. Haij journey of a lifetime. BMJ 2005:330:133-7.

2 Ahmed O Arabi Y, Memish Z. Health risks at Haij. Lancet 2006:367:1008-15

3 Balkhy H, Al-Hajjar S. Avian influenza: are our feathers ruffled? Ann Saudi Med 2006;26:175-82.

4 Balkhy H, Memish Z, Bafaqeer S, Almuneef M. Influenza a common viral infection among Hajj pilgrims: time for routine surveillance and vaccination. J Travel Med 2004;11:82-6.

5 Al-Asmary S, Al-Shehri AS, Abou-Zeid A, Abdel-Fattah M, Hifnawy T, El-Said T. Acute respiratory tract infections among Hajj medical mission personnel, Saudi Arabia. Int J Infect Dis 2006, Aug 11; Epub ahead of print.

6 El Bashir H, Haworth E, Zambon M, Shafi S, Zuckerman J, Booy R. Influenza among U.K. pilgrims to Hajj, 2003. Emerg Infect Dis 2004;10:1882-3.

7 Al-Shehry AM, Al-Khan AA. Pre-Hajj health related advice, Makkah. Saudi Epidemiol Bull 1999;6:29-31

8 Choudhry AJ, Al-Mudaimegh KS, Turkistani AM, Al-Hamdan NA. Hajjassociated acute respiratory infection among hajjis from Riyadh. Eastern Med Health J 2006;12:300-9.

9 Katme AM. Muslim teaching gives rules for when hands must be washed. BMJ 1999;319:520.

10 Shafi S, Rashid H, Ali K El-Bashir H, Haworth E, Memish ZA, Booy R. Influenza vaccine uptake among British Muslims attending Hajj, 2005 and 2006. BMJ 2006 doi: 10.1136/bmj.39051.734329.3A.

11 Mustafa AN, Gessner BD, Ismail R, Yussof AF, Abdullah N, Ishak I, et al. A case control study of influenza vaccine effectiveness among Malaysian pilgrims attending the Haij in Saudi Arabia Int J Infect Dis 2003,7:210-4.

12 Hayden FG, Pavia AT. Antiviral management of seasonal and pandemic influenza. J Infect Dis 2006:194:S119-26.

13 Leventhal A, Ramlawi A, Belbiesi A, Balicer RD. Regional collaboration in the Middle East to deal with H5N1 avian flu. BMJ 2006;333:856-8.

doi 10.1136/bmj.39052.628958.BE

\section{Child safety in cars}

\section{Good practice is now reinforced by new legislation}

See also Practice p 1205
$\mathrm{I}$ n 2005 in the United Kingdom, 24 children aged under 10 years were killed while travelling in cars and a further 226 were admitted to hospital. ${ }^{1}$ The numbers of injured children who were wearing baby and child restraints or seat belts were not given, but such devices are known to be effective in reducing the severity of injury. ${ }^{2-4}$ When used properly, child passenger restraints reduce injury by $90-95 \%$ for rear facing systems and $60 \%$ for forward facing systems compared with not using a restraint. ${ }^{5}$

On 18 September 2006 the law on carrying babies and children in cars, vans, and goods vehicles in the UK changed to correspond with the rest of the European Union. Limited use of child restraints and seat belts in cars in the UK has been required by law since 1983 in the front seat and 1989 in the rear seat. However, the UK adopted a minimalist approachbaby and child seats had to be used only if one was available in the vehicle-a fact not widely publicised for obvious safety reasons. The legislative changes reinforce what should always be good practice: that all children in cars should use appropriate child restraints and that adult seat belts are intended for adults, not children.

The law states that children under 3 years cannot legally travel in cars unless they are in an appropriate baby or child seat (usually a rear facing baby seat for children under 1 year and a child seat with an integral harness for older children). The one exception is when a baby or young child is carried in a taxi and no child restraint is available; in these circumstances the child may travel unrestrained on the back seat.
The law is more complicated for children over 3 years. When a child is 12 years old or reaches $1.35 \mathrm{~m}$ an adult seat belt can be used without increasing the risk of injury. Children under 12 years who are less than $1.35 \mathrm{~m}$ tall are now required to use appropriate child restraints. Such restraints are child seats with integral harnesses or so called booster seats, in which the adult seat belt passes around the front of the child; the function of the booster seat is to position the belt correctly on the child's body.

There is one exception for children over 3 years, the "unexpected necessity" clause. This clause allows children to use an adult seat belt for an unplanned but necessary short journey if a child restraint is not available. The Department for Transport emphasises that this is not intended to cover regular school runs but is applicable when, for example, a child cannot be collected as planned and alternative arrangements are made at short notice. When the alternative to using an adult seat belt is leaving the child outside the school gate the exemption seems sensible, although it should be monitored through observational studies commissioned by the Department for Transport to detect abuse.

Failure to comply with the law can result in a $£ 30$ ( $444 ; \$ 59)$ fixed penalty notice or a fine of up to $£ 500$ if the case goes to court. Although policing of the child restraint law has been barely visible in the past, in 2004 around 200000 fixed penalty notices were issued. How strongly the police intend to (or need to) enforce the recent changes remains to be seen. A constructive approach will probably be taken initially, with police 
forces working with local authority road safety officers to ensure that parents and carers understand the law. Police officers are unlikely to start carrying height measuring equipment in their cars to enforce the detailed provisions of the law.

Despite changes in the past 10 years, child restraints are still not that easy to use consistently. Child seats with Isofix attachments that are plugged into corresponding anchorages in cars are becoming more common in the UK. This system decreases the likelihood that the seat will be fitted incorrectly, but such seats can be twice the price of those restrained by an adult seat belt. Although not an argument against using Isofix, this is an example of poorer families being disadvantaged compared with better off families by the cost of technological development.

Although the change to the legislation is welcome, we must remember that child restraints and seat belts are secondary safety measures. They have the potential, when fitted correctly and used consistently, to reduce the severity of injuries and the likelihood of death. They do not prevent car crashes, however, and prevention should continue to be the long term aim.

Michael Hayes projects director

(mike.hayes@capt.org.uk)

Child Accident Prevention Trust, London EC1R 3AJ

Competing interests: None declared.

1 Department for Transport. Road casualties Great Britain. London: Stationery Office, 2006.

2 National Highway Traffic Safety Administration. Research note: revised estimates of child restraint effectiveness. Report 96.855 . Washington, DC: US Department of Transportation, NHTSA, 1996.

3 National Highway Traffic Safety Administration. Traffic safety facts, 1999. A compilation of motor vehicle crash data from the fatal analysis reporting system and the general estimates system. DOT HS 809 100. Washington, DC: NHTSA, 2000.

4 Children's Safety Network. Childhood injury: costs and prevention facts. Child safety seats: how large are the benefits and who should pay? Landover, MD: CSN, Economics and Insurance Resource Center, 1997.

5 European Transportation Safety Council. Priorities for EU motor vehicle safety design. Brussels: ETSC, 2001.

doi $10.1136 /$ bmj.39048.685787.80

\section{Treatment of dementia in the community}

\section{Occupational therapy improves function and reduces the burden on care givers}

$\mathrm{T}$ he paper by Graff and colleagues in this week's $B M J$ comes at a time of disappointment and confusion for people with dementia and for those who care for them. ${ }^{1}$ The National Institute for Health and Clinical Excellence (NICE) recently recommended that cholinesterase inhibitors should not be used in patients with mild dementia, on the grounds that the modest benefits of treatment do not justify the healthcare costs. ${ }^{2}$ The hope that atypical antipsychotic drugs might play an important role in the management of non-cognitive aspects of dementia has been thwarted by evidence of adverse cerebrovascular events and increased mortality. ${ }^{3}$ Against this background, Graff and colleagues' study provides hope for effective non-pharmacological interventions and an example of how to design research into care for dementia.

The trial participants comprised 135 people with mild to moderate dementia who were living in the community. It found that a five week occupational therapy intervention (about 18 hours for each patient and care giver) significantly increased the functioning of the patient and reduced the burden on the care giver. The number needed to treat to produce a clinically significant improvement in patients' function and burden to care givers at six weeks was impressively low. For patients' daily functioning, the number needed to treat was $1.3(95 \%$ confidence interval 1.2 to 1.4) when the assessment of motor and process skills scale was used, and 1.5 (1.4 to 1.6) if the interview of deterioration in daily activities in dementia scale was used. For burden on care givers, as assessed by the sense of competence questionnaire, the number needed to treat was 2.5 (2.3 to 2.7). Furthermore, the benefits were maintained at three months.
The trial is noteworthy in three respects-the choice of the target population, the type of intervention, and the definition of treatment outcome. The target population comprised people living with dementia and their carers. Most people with dementia live in the community and have mild to moderate disease. Almost all have a primary care giver. The care giver's role is crucial, as the daily functioning of people with dementia depends on the quality of care received at home. ${ }^{4}$ The quality of the relationship with the care giver is an important predictor of whether someone with dementia will stay in the community or enter an institution. ${ }^{5}$ By focusing the intervention on both the patient and their carer, Graff and colleagues have looked at this crucial relationship in the community setting.

The intervention comprised a personalised programme in which patients and care givers learnt to choose and prioritise meaningful activities they wanted to improve. The therapist then helped them develop optimisation and compensation strategies that effectively used their skills and personal and environmental resources. Thus, the intervention was not just tailored to the circumstances of the patient and their carer but also to their values and aspirations.

The methodology reflects the integrated approach adopted by occupational therapists supporting people with dementia and their carers. The trial justifies such an approach and points to how it can be optimised. This "selection optimisation compensation" model can identify strategies associated with healthy ageing in the population. ${ }^{67}$ The current study shows that this approach can also be used to develop effective interventions to help people adapt to the demands of dementia, despite their limited learning abilities. 
The study end points focused on patient function and the wellbeing of care givers. People with dementia and their care givers will recognise these end points as valid. The association of these outcomes with the risk of entering institutional care makes them important for appraising the impact of the intervention on healthcare costs. The trial shows that the primary focus of research should be the patient and their carer, and that interventions and outcomes must reflect this.

Importantly the patients in the study were already stable on cholinesterase inhibitors at the outset. The benefits of the intervention are therefore in addition to those of medication. It would be interesting to assess the effect of the intervention in the absence of cholinesterase inhibitors or to compare it with a cholinesterase inhibitor in a head to head trial.

Non-pharmacological interventions in dementia have a long history, but until recently they have not been tested in high-quality controlled trials. ${ }^{8}$ This is unfortunate because interventions such as the one described by Graff and colleagues have the potential to deliver additional benefits to those obtained with drugs alone, as they encompass the patient, their carer, and their environment.

The promising results of this study need to be replicated, and further trials need to be refined and extended. This requires building research capacity and increasing resources and funding to the multidisciplinary teams that deliver care for dementia in the community. To achieve this goal, however, we need to deal with the complex factors that have caused non-pharmacological research into dementia to lag so far behind its pharmacological counterpart. We also need to examine the structure and funding of research to bring it closer to the Alzheimer's Society's vision of a proportionate balance between cause, care, and cure. ${ }^{9}$

Jeannette Golden senior registrar in old age psychiatry (jeannette.golden@gmail.com)

Brian Lawlor Conolly Norman professor of old age psychiatry

St James's Hospital and Trinity College, Dublin, Ireland

Competing interests: BL has received honorariums and hospitality from drug companies that market cholinesterase inhibitors.

1 Graff MJL, Vernooij-Dassen MJM, Thijssen M, Dekker J, Hoefnagel WHL, Olde-Rikkert MGM. Community based occupational therapy for patients with dementia and their care givers: randomised controlled trial. patients with dementia and their care givers: ran

2 National Institute for Health and Clinical Excellence. Donepezil, galantamine, rivastigmine (review) and memantine for the treatment of Alzheimer's disease. Technology appraisal TA 111. London: NICE, 2006. www.nice.org.uk/guidance/TA111.

3 Schneider LS, Dagerman K, Insel PS. Efficacy and adverse effects of atypical antipsychotics for dementia: meta-analysis of randomized, placebo-controlled trials. Am J Geriatr Psychiatry 2006;14:191-210.

4 Graff MJL, Vernooij-Dassen MJM, Zajec J, Olde-Rikkert MGM, Hoefnagels WHL, Dekker J. How can occupational therapy improve the daily performance and communication of an older patient with demendaily performance and communication of an older patient with dem

tia and his primary caregiver? A case study. Dementia 2006;5:503-32.
Spruytte N, Van Audenhove C, Lammertyn F. Predictors of institutionalSpruytte N, Van Audenhove C, Lammertyn F. Predictors of institutionali-
zation of cognitively-impaired elderly cared for by their relatives. Int J Geriatr Psychiatry 2001;16:1119-28.

6 Freund AM, Baltes PB. Life-management strategies of selection, optimization, and compensation: measurement by self-report and construct validity. J Pers Soc Psychol 2002;82:642-62.

7 Jopp D, Smith J. Resources and life-management strategies as determinants of successful aging: on the protective effect of selection, optimization, and compensation. Psychol Aging 2006;21:253-65.

Ayalon L, Gum AM, Feliciano L, Arean PA. Effectiveness of nonpharma-

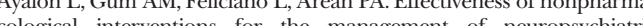
cological inteventions for the managenent of neuropsychiatric 2006;166:2182-8.

9 Alzheimer's Society. Quality research in dementia. London: AS, 2005. www.qrd.alzheimers.org.uk/documents/

AlzheimersSociety_ResearchStrategy_Aug2005.pdf

doi 10.1136/bmj.39051.484421.80

\section{The future of primary care nurses and health visitors}

\section{Increasing fragmentation threatens the primary healthcare team}

$\mathrm{N}$ ew policies, new contracts, and financial pressures have altered the roles of primary care nurses and health visitors and their relationship with general practitioners (GPs). How will the primary care trust survive?

\section{Roles in different countries}

In remote areas of some rich nations (such as rural Australia) highly trained nurses provide the core of primary medical care for adults and children. In many developing nations (such as Bangladesh and China) locally trained nurses tend to work in hospitals and private clinics in towns, whereas health care in rural communities often depends on lay medical aides and occasionally doctors. In the United States nurses manage care for chronic disease.

In the United Kingdom, some nurses are employed by independent contractor GPs, while others including health visitors are attached to general practice teams but are paid and managed by primary care organisations. They have worked alongside GPs for many years: good communications between such primary care professionals lead to better quality care for patients with complex clinical and social problems.

\section{Alternative ways of working}

Pressure to save money, improve patient access, and tackle shortages in the medical workforce has led the UK government to develop alternatives to traditional general practice. These include National Health Service (NHS) walk-in centres, NHS Direct, primary care trust medical services, and alternative provider medical services. These changes threaten the traditional primary healthcare team and raise questions about the future of primary care nursing and health visiting.

Nurses and health visitors are withdrawing from primary healthcare teams in England for two main reasons. Firstly, their numbers are declining. A 
third of primary care nurses and health visitors are approaching retirement age, ${ }^{2}$ and training restrictions, vacancy freezes, and staff cuts have exacerbated the shortfall. The number of health visitors is the lowest for 12 years. ${ }^{3}$ Recent proposals in Scotland advocate that specialist community nurses and health visitors are replaced by generic community nurses. ${ }^{4}$ In England, some health visitors have moved to new children's centres. The recruitment of "community matron" managers from district nursing has also left gaps in the primary care nursing workforce.

\section{Increasing competition}

Secondly, primary healthcare trusts are threatened by competition, which has altered the way that primary care providers view each other. The UK government is keen to develop alternative ways of providing health care, and by stimulating competition it hopes to improve quality and value for money. Clinical services run mainly by nurses and nurse practitioners are thought to provide better access for patients at less cost. Such nurses may take on senior posts with considerable strategic and operational responsibility. In England, practice based commissioning, with general practices taking control of budgets for secondary care services, may stimulate other innovations where privately or self employed nurses work for specialist services.

None the less, other factors may encourage nurses to remain in primary healthcare trusts led by GPs. Primary care nurses see an opportunity to become entrepreneurs ${ }^{5}$ as alternative (private) providers embracing "social enterprise." However, they are hesitant to leave the clinical support, relative financial security, and pensions provided by the NHS. In addition, the 2003 GP contract $^{6}$ has stimulated many practices to think about staffing and skill mix, ${ }^{7}$ which has led to initiatives to improve the professional status of nurses. New systems that reward practices for good management of chronic diseases have highlighted the financial and clinical importance of input from nurses. Many general practice nurses are acquiring advanced skills in diagnosis and prescribing; others are taking strategic and leadership roles or even becoming practice partners.

\section{Targeted health promotion}

Fitzpatrick $^{8}$ suggests that many aspects of promoting healthy lifestyles could carry on outside general practice with lay trainers so that GPs and primary care nursing professionals would have more time for patients with acute and chronic diseases. Although general practice does need to define its boundaries regarding social care and education, we think that targeted promotion led by nurses still has a place in general practice.

It is time to re-examine the divisions of power, responsibility, and rewards within general practice primary healthcare trusts. We believe that such trusts should remain central to the provision of primary care but wonder whether changes in the role of primary care nurses and health visitors, and the fragmentation of the organisations that employ them, will have a negative effect on patient care and discourage democratic team work.

\section{Christopher Derrett general practitioner}

(c.j.derrett@qmul.ac.uk)

Barton House Group Practice, London N16 9JT

Lydia Burke senior lecturer

(l.burke@mdx.ac.uk)

Middlesex University, London N19 5LW

Competing interests: None declared.

1 Wagner EH. The role of patient care teams in chronic disease management. BMJ 2000;320:569-72.

2 Audit Commission. A focus on general practice in England. AC, 2002. www.rcgp.org.uk/pdf/ISS_SUMM02_11.pdf.

Amicus. Hewitt ignored warnings on health visitor crises. 2006. www.amicustheunion.org/defaultaspx?page $=3826$.

4 Scottish Executive Health Department. Review of nursing in the community steering group minutes. SEHD, July 2006. www.scotland.gov.uk/Topics/ Health/NHS-Scotland/nursing/communitynursing/Steering-Group/ Health/NHS-Scotland/nursing
steering-group-minutes/July.

5 Young L. Community nurses, social enterprise and community interest Young L. Community nurses, social enterp
companies. Primary Health Care 2006;16:5.

6 Department of Health. New primary care contracts-what they mean for employers of nurses in general practice. London: DOH, 2003. www.natpact.nhs.uk/uploads/pcc/Employers_of_GP_nurses.pdf.

7 Scottish Executive Health Department. Framework for nursing in general practice. SEHD, 2004. www.sehd.scot.nhs.uk/practicenursing/index.htm. Fitzpatrick M. The future of general practice. Br J Gen Pract 2006;56:801. doi $10.1136 /$ bmj.39043.386019.80 